\section{A utilização da noção de eqüidade na alocação de recursos em tempos do pensamento (neo)liberal: anotações para o debate}

The equity utlilisation for money

in (neo)liberal era: notes for discussion

Paulo Eduardo Elias 2

Artigo de interesse por tratar de um tema bastante presente no debate internacional, derivado especialmente dos países do capitalismo central e estimulado pelas agências multilaterais. Ademais, trata de uma discussão sobre situação concreta na qual, à época, o gestor estadual da saúde apresentava-se em disputa política com o gestor federal no debate sobre a condução do SUS, em que se sobressaía justamente os aspectos relacionados ao financiamento da saúde no País, e os critérios para a distribuição do recurso financeiro, matéria esta recorrente pela corrente municipalista da Reforma Sanitária Brasileira.

As autoras têm razão ao apontar a relevância da discussão sobre o tema a partir da excelente e aplicada revisão da literatura internacional, ainda que desprovida de qualquer assinalamento sobre o significado político do debate e das ações implementadas em diversos países. No entanto, contrariamente à situação tratada no artigo, na maioria dos países apontados, o debate se apresenta de modo substantivo por envolver aportes financeiros minimamente adequados aos fins pretendidos, sobressaindo a preocupação com os resultados e não meramente com o processo em si.

O financiamento da saúde requer patamares mínimos de recursos para se conciliar com o objetivo da eficácia social dos serviços prestados. E como apresentado fartamente pela literatura nacional e no mundo da política, 0 quadro do financiamento, ainda que tenha avançado na última década, configura-se por vários ângulos bastante desfavorável ao SUS. No tocante ao equilíbrio do volume de recursos, a participação de Estados e municípios mostra-se deficitária mesmo considerando-se o grande esforço orçamentário de muitos representantes destes entes federados, uma vez que a União responde por cerca de $60 \%$ do financiamento destinado ao SUS. M esmo com a adoção plena da Ementa Constitucional 29, fato que hoje não ocorre em boa parte dos Estados e em menor escala nos municípios, o mon- tante total de recursos alocados na saúde se mostra insuficiente diante das necessidades derivadas do projeto contemplado pela Constituição, isto é, a construção de um sistema de saúde universal e igualitário num país de grande extensão territorial e porte populacional. Esta tarefa, que por si exige grande competência, trabalho contínuo e persistente, se transforma em enorme desafio ao se considerar 0 grau de desigualdade social a que a população está submetida e a inserção econômica do País na periferia do capitalismo.

Deste modo, a situação trazida pelo artigo chama a atenção ao não precisar os valores efetivamente transferidos aos municípios, situando-os entre $R \$ 186,34$ e $R \$ 1,60$. Não obstante, tomando-se o que seria o valor médio a ser transferido para o conjunto dos municípios se a distribuição fosse igualitária, denota a inexpressividade do valor envolvido na transferência, isto é, apenas $R \$ 6,44$ per capita/ano ou $\mathrm{R} \$ 0,54 /$ mês, muito longe de contribuir para 0 encaminhamento ou produzir algum impacto duradouro na assistência à saúde da população, mesmo na atenção básica para o conjunto dos gaúchos, como se espera da preocupação da esfera estadual de gestão. M uitos dirão que este valor mesmo extremamente insuficiente é meIhor que nada e, à primeira vista, relativamente ao não repasse, não há como discordar dessa asserção. M as 0 aspecto central está longe de se configurar como este, ainda que com muita freqüência ele seja argüido como nuclear no discurso de um determinado pensamento dominante na saúde que concebe os meios desvinculados dos fins. Quanto a este aspecto, vale notar que os meios se qualificam por referência às finalidades e não por si mesmos. E justamente quanto aos fins 0 artigo e o processo nele tratado são silentes, a meu juízo, em parte pela diminuta expressão do repasse realizado, mas não só. V ejamos este aspecto mais detalhadamente a partir das indagações suscitadas por estetrabalho.

A questão de fundo no debate apresentado se refere ao surrado, mas ainda não superado, tema da descentralização, este também colocado em pauta no debate internacional em meados da década de 1970, com o mesmo apoio de agências multilaterais e de governos de países

\footnotetext{
2 Departamento de M edicina Preventiva. Faculdade de M edicina da U niversidade de São Paulo.
} 
industrializados como a Inglaterra, concomitante à ascensão do predomínio do pensamento liberal na formulação das políticas econômicas. $M$ ais recentemente, a ele se agregou o tema da eqüidade que, tomado em certa vertente com propósito de "domesticar" a força do conceito originário, vem ganhando espaço e fôlego a partir dos anos 90, impulsionado pelas mesmas forças e instituições que vem pautando 0 debate no campo da saúde em escala global. Portanto, do ponto de vista teórico conceitual, trata-se da relação ou articulação entre descentralização e eqüidade que merece ser analisada.

A qualificação da descentralização está vinculada à concretude da sua real ização. N esse sentido, tanto a descentralização como a centralização só ganham substância analítica a partir das condições objetivas em que se implementam. Em conseqüência, os elementos mais relevantes para a análise deixam de ser os princípios e as diretrizes da descentralização, mas sim as condições sociopolíticas dadas para a sua implementação (Bobbio,1993). Assim, a descentralização não adquire concretude simplesmente a partir do enunciado de seu ideário, mas somente vem a obtê-la a partir da interação com as condições políticas e sociais em que se realiza, estas, em última instância, as determinantes da sua configuração. Em outros termos, a descentralização nada molda, antes se amolda à realidade histórica determinante da sua implementação.

0 tipo de descentralização fundada exclusivamente na égide da razão financeira ten de a focalizar e pulverizar os problemas sociais a serem enfrentados e, deste modo, termina por subordinar a dimensão política à lógica operativa do argumento financeiro num movimento de imposição da hegemonia da dimensão técnica sobre as demais, com o agravante de que dada a própria natureza da racionalidade técnica ela opera através da fragmentação e atomização dos problemas. Ademais disto, a racionalidade técnica enfatiza sobremaneira os resultados a serem alcançados segundo parâmetros de eficácia exclusivamente técnicos, o que nem sempre coincide com a de natureza social, esta última balizada por outros padrões, dentre eles a capacidade de responder adequadamente às expectativas de atendimento geradas na sociedade.

Por outro lado, a descentralização coloca uma maior exigência sobre o poder local em relação ao financiamento dos serviços de saúde e aos modelos de atenção à saúde, requerendo um grau mínimo de competência técnica e política da esfera local como um requisito para que ocorra uma descentralização efetiva. Acontece que nem sempre as autoridades locais têm maior clareza sobre essas questões, e com freqüência o nível local pode estar sob o controle de oligarquias políticas. Assim, há que se indagar sobre a capacitação técnica da esfera local para exercer as atribuições que lhe são conferidas, ao se pretender uma descentralização que preserve um mínimo de eficácia social, isto é, que responda de modo social mente competente às demandas da população.

Em relação à eqüidade, uma rápida revisão na literatura sobre o termo revela a particularidade como ele vem sendo tomado na área da saúde, muitas vezes recebendo um tratamento econométrico ao se tentar qualificá-lo. No entanto, este termo tomado como conceito não se presta a essas medições. Ao se consultar a produção da área de ciências humanas fica mais notável o contraste entre os dois tipos de abordagem. Há também a se considerar que o conceito de eqüidade não é bem estabelecido e, portanto, torna-se de difícil operacionalização. Vale destacar que conceitos são recursos de difícil operacionalização, pois como tais constituem elementos do mundo das idéias e não do das coisas e, no caso do conceito de eqüidade, há dificuldades adicionais ao se intentar sua operosidade.

$\mathrm{N}$ a tradição filosófica, o conceito clássico, tal qual esclarecido por Aristóteles e reconhecido pelos juristas romanos, o sentido indica 0 apelo à justiça quando voltado à correção da lei em que se exprime a justiça. Diz Aristóteles que a própria natureza da eqüidade é a retificação da Lei onde esta se revela insuficiente pelo seu caráter universal. A lei tem necessariamente caráter geral, por isso revela-se às vezes de aplicação imperfeita ou difícil em casos particulares.

Nestes casos, isto é, nos particulares, a eqüidade intervém para julgar, não na base da lei, mas na base da justiça que a mesma lei deve realizar. Portanto, segundo Aristóteles, o justo e o eqüitativo são a mesma coisa, podendo se inferir que o eqüitativo é superior, não ao justo em si, mas ao justo formulado em uma lei que em virtude da sua universalidade está sujeita ao erro.

$\mathrm{N}$ a tradição filosófica moderna, fundamentando-se em conceito análogo ao aristotélico, Kant considerava, todavia, que a eqüidade não se presta a uma autêntica reivindicação jurídica e que, portanto, cabe não aos tribunais, mas 
ao tribunal da consciência. N ota-se, a gênese da eqüidade como questão jurídica e posteriormente conceituada como uma questão moral.

Numa e em outra situação, os desdobramentos e as repercussões para a área da saúde são de grande monta. Deste modo, são perfeitamente inteligíveis as deficiências em relação aos marcos conceituais da eqüidade referida à área da saúde. Não se pretende justificar pelas deficiências teórico-conceituais o impedimento a que seja adotada como noção orientadora, como norte a ser seguido nas políticas de saúde e na prática dos serviços.

De certo modo, a noção de eqüidade se associa de modo diverso à igualdade e, sobretudo, à justiça, no sentido de propiciar a correção daquilo em que a igualdade agride e, portanto, naquilo que a justiça deve realizar. Tomada neste sentido, a eqüidade requer a igualdade para produzir efeitos, pois se constitui justamente em corretora da situação igualdade, na medida em que a adoção deste recurso se revele imperfeita diante dos objetivos da promoção de justiça. Vale destacar que a descentralização exige, como fundamento, a igualdade entre os entes destinatários da ação descentralizadora.

Por esta linha de pensamento, conclui-se pelo questionamento do uso da noção de eqüidade no presente artigo, por duas ordens de razões mais imediatas, dentre outras. A primeira diz respeito ao requisito da justiça, isto é, a que situação de igualdade se aplica a eqüi dade para se obter a justiça. $O$ argumento do porte populacional do município é completamente insuficiente para produzir este efeito e, na linha da melhor tradição dos sistemas universais como se pretende o SUS, caberia recuperar 0 argumento do acesso igualitário aos serviços e ações de saúde o que está muito além de ser equacionado apenas pela alocação diferenciada de recursose, muito menos, pelo diferencial per capita a ser transferido aos municípios. A segunda razão, conexa a esta, apela para a inadequação da redução da noção de eqüidade a expressões de base matemática para a alocação de recursos financeiros, por mais engenhosas que elas possam se constituir. Claro está que não se obsta a expressão em si, mas a sua qualificação como expressão de eqüidade; e não apenas por justificativas conceituais, mas sobretudo pelas de ordem política no sentido da banalização da noção da eqüidade e de seu (re) ordenamento no sentido da perda de intensidade da noção original e sua adequação aos marcos do debate pautado pelo interesse ideológico expresso pe- lo pensamento (neo) liberal dominante desde 0 final do século 20 e corrente em certos setores do pensamento da saúde.

A mesma linha de argüição se aplica ao famigerado artigo 35 da Lei Orgânica da Saúde. Sobre essa Lei cabe advertir as reações de alguns autores no sentido de identificarem vários de seus dispositivos como constituindo obstáculos para a implementação de um real processo de descentralização na saúde. Segundo Vianna (1991), sob inspiração do projeto encaminhado pelo Poder Executivo, o Congresso legitimou um extenso conjunto de regras, de cunho centralizador em inúmeros pontos, e que violam a autonomia estadual e municipal, e complementa: vários dispositivos da Lei 8.080/90 (e da Lei $8.142 / 90$ ) restringem o princípio constitucional de descentralização.

No que toca ao artigo 35, a dificuldade em regulamentá-lo se deve às razões de ordem técnica, sobretudo em relação à inclusão de critérios epidemiológicos na condição de discernimento para o cálculo das transferências financeiras. O corre que os indicadores epidemiológicos não se prestam para fins de discriminação em situações que exigem decisões políticas prévias, como a que trata 0 artigo em tela, dado que estes indicadores servem apenas para a caracterização da situação de saúde das populações sem, contudo expressar qualquer juízo de valor sobre a mesma para fins de repartição dos recursos financeiros. Em outras palavras, dadas as suas próprias características, os critérios epidemiológicos (M endes Gonçalves, 1994) se adéquam estritamente para apontar as necessidades de atenção à saúde segundo parâmetros da morbi-mortalidade populacionais, ou no jargão do Planejamento em Saúde a definição da situação de saúde da população, e não como critério de escolha entre duas ou mais situações para o estabelecimento de prioridades na alocação de recursos. Estas dependem, sobretudo de diretrizes prévias que devem ser estabelecidas por um processo de negociação política que implique a representação dos interesses das distintas efferas de governo.

Por fim, é estimulante perceber o compromisso político e social com a construção de um sistema de saúde fundado no primado da justiça e preocupado com a desigualdade social, ainda que os percalços neste caminhar sejam inúmeros, a apontar os desafios teórico-conceituais e para as práticas colocados para os centros produtores de conhecimentos e os gestores da saúde. A construção de um sistema de 
saúde como o SU S na periferia do capitalismo e em países com a dimensão e grau de desigualdade como vigente no Brasil, não se constitui em linha reta, mas supõe idas e vindas com inúmeras tentativas como a apresentada neste artigo. No entanto, a consecução final deste escopo exige de um lado uma postura crítica comprometida com os interesses dos socialmente excluídos e a de outro a formulação e implementação de políticas de Estado para cristalizar e ampliar os caminhos para a efetivação da eficácia social do sistema de saúde.

\section{Referências bibliográficas}

M endes Gonçalves RB 1994. Tecnologia e organização social das práticas de saúde. Hucitec-Abrasco, São Paulo-Rio de Janeiro.

Abbagnano N 1970. Dicionário de Filosofia. Editora M estre Jou, São Paulo.

Berlinguer G 2004. Bioética cotidiana. Editora Universidade de Brasília.

Bobbio N 1993. Dicionário de Política. (5a ed.). Editora Universidade de Braślia.

Borja J 1987. Descentralización del Estado y democracia local, pp. 21-36. In J Borja J. M anual de Gestión M unicipal Democrática. Instituto de Estudos de Administración Local, M adri.

Tobar F 1991. O conceito de descentralização: usos e abusos. Plan. Pol. Pub. 5:31-51.

Vianna SM , Piola SF, Guerra AJ \& Camargo SF 1991. O financiamento da descentralização dos serviços de saúde: critérios para transferências de recursos federais para estados e municípios. I pea, Brasília. (Documento de Política/n. 3).

\section{Distribuição de recursos financeiros e eqüidade: uma relação delicada na saúde} Financial resources distribution and equity: a delicate relationship in health

\section{Patrícia Ribeiro 3}

Os estudos internacionais e nacionais sobre eqüidade em saúde, que vêm se acumulando desde a década de 1970, e os resultados de várias iniciativas nacionais de alocação de recursos governamentais, setoriais e extra-setoriais, visando mais justiça no processo saúde/doen-

\footnotetext{
3 Departamento de Ciências Sociais, EN SP/Fiocruz.
}

ça/saúde, em vários países do mundo, criaram as condições para que, na atualidade, se comece a avaliar a implementação de políticas públicas com este propósito. A complexidade das escolhas a fazer, das decisões a tomar, das bases científicas exigidas e das análises requeridas para uma avaliação de seu impacto na efetiva redução de desigualdades ocupa cada vez mais espaço no campo de preocupações de pesquisadores e governantes.

Sen (2001), respondendo à pergunta "why health equity?", em nota apresentada à 3a Conferência Internacional sobre The Economics of $\mathrm{H}$ ealth: Within and Beyond $\mathrm{H}$ ealth Care, ocorrida em York, Inglaterra, em 2001, identifica claramente esta complexidade ao abordar dificuldades para uma compreensão adequada das demandas por eqüidade em saúde: The real work begins with the specification of what is to be equalized. The central step, then, is the specification of the space in wich equality is to be sought, and the equitable accounting rules that may be following in arriving at aggregative concerns as well as distributive ones. The content of theories turns on the answers to questions as "equality of what?" and "equity in what form?" (Sen, 2001).

Klein (2003), em reunião da H ealth Equity Network (HEN), organizada com o objetivo de iluminar as relações entre desigualdades em saúde, políticas públicas e implementação, ocorrida na London School of Hygiene and Tropical M edicine, em 2002, apresentou a seguinte conclusão sobre o evento em seu comentário "making policy in a fog": O nly one clear conclusion can be drawn from the various papers discussed at the conference... This is that policy making about health inequalities takes place in a fog of disagreement about goals, controversy about causes and uncertainty compounded by ignorance about means. The challenge is how best to make sensible decisions in the absence of both consensus about what ought to be done and evidence about how best to set about achieving whatever policy aim we choose to set for ourselves (Klein, 2003).

M ais recentemente, Graham \& Kelly (2004), em artigo publicado pela $\mathrm{H}$ ealth $\mathrm{D}$ evelopment A gency, do $\mathrm{N}$ ational Health Service (NHS), no qual examinam temas relacionados a desigualdades socioeconômicas em saúde, destacaram a necessidade de as políticas públicas atuarem não apenas na melhoria da saúde dos mais pobres, mas no estreitamento dos gaps entre os grupos e segmentos sociais e na el evação do ní- 